\title{
Universality of physicians' burnout syndrome as a result of experiencing difficulty in relationship with patients
}

\author{
Zbigniew Sablik ${ }^{1}$, Anna Samborska-Sablik², Jarosław Drożdż
}

1Department of Cardiology, I Chair of Cardiology and Cardiac Surgery, Medical University of Lodz, Poland

2Department of Emergency Medicine and Disaster Medicine, Chair

of Anaesthesiology and Intensive Therapy, Medical University of Lodz, Poland

Submitted: 27 April 2011

Accepted: 12 December 2011

Arch Med Sci 2013; 9, 3: 398-403

DOI: 10.5114/aoms.2012.28658

Copyright (๑) 2013 Termedia \& Banach

\begin{abstract}
The aim of our work is to present the universality of burnout syndrome among physicians worldwide and to demonstrate selected aspects of the relationship between patients and doctors as a common factor predisposing to burnout. We looked up 20 original pieces of research from the Medline database published in the last 10 years to determine the prevalence of burnout among doctors in different countries. In all quoted works a remarkable percentage of doctors of interventional and non-interventional specialties suffered burnout. Because it is the relationship with patients that constitutes a key denominator for their work, in the discussion we have exposed an important aspect of it, destructive patient games, described on the basis of transactional analysis. Since universal burnout causes a deterioration of doctors' service, for the optimal good of the patient to survive preservation of the doctor's well-being in the patient-doctor relationship is needed everywhere.
\end{abstract}

Key words: emotional exhaustion, interpersonal games, personal resources.

\section{Introduction}

The concept of burnout was introduced in 1974 by Freudenberger, who initially observed a progressive loss of energy and diminishing interest in work in volunteers in a center for drug addicts [1]. The next example of burnout syndrome was described in people who work in the caring professions, such as the health services, social workers, psychologists, teachers and policemen [2, 3]. Despite abundant research conducted on burnout syndrome and procedures developed to counteract it [4], we demonstrate in this work that burnout syndrome in doctors is still a significant issue of global extent. This suggests that physicians are commonly exposed to a factor predisposing them to burnout that has still not been taken under sufficient control.

So the aim of this work was to ascertain the universality of burnout syndrome among physicians and to indicate particular aspects of the professional relationship between doctor and patient as important factors leading doctors to burnout.

\section{Defining burnout syndrome}

Freudenberger, the author of the term burnout, assessed it as a state of tiredness or exhaustion, when one fails to achieve the aim of one's job 
in spite of personal involvement [1]. Maslach was the first to independently describe burnout as a 3-dimensional syndrome including emotional exhaustion, depersonalization and reduced personal accomplishment $[4,5]$. A negative work environment, especially work overload, and the belief that they are not able to deliver the high standards of care expected, bring about feelings of permanent nervous strain, irritability and anxiety $[4,5]$. This in turn leads to emotional and physical lassitude $[4,5]$. To avoid becoming more personally involved, a doctor suffering burnout distances himself even further from the patient, treating him superficially, in a formal way, indifferently or with a negative attitude (depersonalization) [4, 5]. What is more, a burnedout employee evaluates the effects of such work as unsatisfactory, experiencing a sensation of diminished personal accomplishment $[4,5]$. Feeling of guilt due to experiencing low competence at work appears, as well as the dread of another working day, and the tendency to avoidance behavior (such as sickness absence from work) or aggressive behavior and even abandonment of work $[4,5]$.

Further descriptions of burnout are based on Maslach's definition. Perlman and Hartman defined burnout as emotional and physical weariness, depersonalization and reduced productivity as a result of chronic emotional stress at work [6]. According to Pines and Aronson, burnout is a state of emotional, mental and physical exhaustion due to chronic exposure to situations of emotional overload [7].

\section{Material and methods}

To assess the prevalence of burnout syndrome among doctors of different specialties and in different work environments, we looked up original papers from the resources of the Medline database, with inclusion and exclusion criteria stated below. Inclusion criteria:

1. Original papers were searched for with the phrases "burnout, professional" and "epidemiology or health survey or prevalence" and, as the next phrase, the name of a medical specialty, whether it was invasive or non-invasive, or, in one case, primary care.

2. Phrases applied to interventional specialties were "surgery" and "intensive care".

3. Phrases relating to non-interventional specialties were "otolaryngology", "ophthalmology", "psychiatry”, "radiology", "oncology”, "gynecology” and "hematology".

4. Data on burnout among family doctors were searched for by adding "family practice or general practitioner or primary care" to the set of 2 phrases described in point 1.

5. The study group of physicians described in an original paper should consist of optimally about 100 physicians or more; the lowest number of physicians in a study group should be close to 30 .
6. Papers discussing factors predisposing doctors to burnout were preferable.

7. Papers published in the last 10 years were preferable; an older one was taken into account due to the particularly high number of the study group. Exclusion criteria:

1. Original papers concerning a low number of the study group of physicians, significantly below 30 .

2. If a previously chosen paper concerned doctors' burnout in a particular country, a consecutive paper concerning another country was preferable, unless a further paper, regarding the same country, was considered which especially fulfilled the inclusion criteria stated in point 6 or 7 above.

3. If a previously chosen paper concerned doctors' burnout in a particular year, a consecutive paper concerning a different year was preferable, unless another paper, regarding the same year, was considered which especially fulfilled the inclusion criteria stated in point 6 or 7 above.

4. If a previously chosen paper concerned doctors' burnout in a particular work environment, a consecutive paper concerning another environment was preferable, unless another paper regarding the same environment was considered which especially fulfilled the inclusion criteria stated in point 6 or 7 above.

Because we wanted to preserve a concise style in presenting information on burnout among doctors, we finally selected a total of 20 original papers describing the issue of the universality of burnout syndrome among doctors of different specialties, in diverse countries, various medical care systems, miscellaneous work environments and in different time spans for the research on burnout.

As planned, the results of these papers were collected in 3 groups: the prevalence of burnout among anesthesiologists and physicians of an interventional specialty, among family doctors and among physicians of other specialties.

\section{Results}

Based on the assessment of intensity in three rudimentary dimensions of burnout syndrome, the results of the research given below document the enormous prevalence of the syndrome in doctors of interventional and non-interventional specialties.

\section{Prevalence of burnout among physicians of interventional specialties and anesthesiologists}

Conducted in the United Kingdom, a survey of over 500 vascular and colorectal surgeons revealed that $1 / 3$ of them revealed features of burnout syndrome [8]. As many as 3/4 of enrolled doctors intended to take early retirement before reaching pension age [8]. Fifty percent of 61 orthopedic and trauma surgeons examined in Saudi Arabia displayed emotional exhaustion and depersonalization [9]. 
Frade recognized burnout syndrome in 13\% of nearly 300 Spanish anesthesiologists [10]. Astonishing outcomes were found in a survey of Portuguese anesthesiologists. Emotional exhaustion was recognized in $57.8 \%$ and depersonalization in as many as $91 \%$ ! [11]. In Germany 1/4 of 89 enrolled anesthesiologists scored high values of emotional exhaustion and depersonalization, while in $1 / 5$ of them a sense of low personal accomplishment was found [12]. The next 1/4 of physicians involved in the study were considered as being at risk of occurrence of burnout syndrome [12].

\section{Burnout syndrome among family doctors}

Lee found that almost $50 \%$ of 123 Canadian family doctors achieved high degree of emotional exhaustion and depersonalization [13]. Similar to these results, the prevalence of emotional exhaustion (53\%) and depersonalization (42\%) was observed among family doctors in Majorca [14].

A study on a group of nearly 500 Hungarian family doctors revealed emotional exhaustion in $30 \%$, depersonalization in $60 \%$, and low personal accomplishment in $100 \%$ of enrolled physicians [15]

Other interesting results were highlighted in 2 surveys conducted in Switzerland. In the first, a moderate or high degree of burnout was recognized in $1 / 3$ of almost 1800 family physicians [16]. In the second study, a comparison of prevalence of burnout syndrome among oncologists, pediatricians and family doctors was assessed [17]. All examined groups exhibited a similar prevalence of known features of burnout, including emotional exhaustion in $33 \%$, but the most prominent risk of its occurrence was found only in family doctors [17].

In 2008 a survey called the European General Practice Research Network Burnout Study Group Study (EGPRN) was published, involving nearly 1400 family doctors in 12 countries [18]. In $43 \%$ of studied physicians, an elevated degree of emotional exhaustion was observed, in 35\% a high degree of depersonalization, and in $32 \%$ a sense of low personal professional achievement. Only $1 / 3$ of examined physicians did not reach high values of burnout in any of its 3 dimensions [18].

\section{Burnout syndrome among physicians of other specialties}

In the United States, a high or moderate state of burnout syndrome was discovered in $84 \%$ of 107 professors of otolaryngology [19]. What is more, in only $9 \%$ of 101 professors of ophthalmology were features of burnout syndrome not found [20].

Two thirds of psychiatrists from New Zealand revealed a moderate or high degree of emotional exhaustion and low sense of personal accomplishment [21]. A high degree of emotional exhaustion was also confirmed among Italian psychiatrists [22].
Almost $80 \%$ of Polish radiologists exhibited a high or moderate degree of burnout syndrome [23].

An enormous prevalence of burnout syndrome was also found among Brazilian oncologists $-69 \%$ [24]. A similar occurrence of burnout was noted in a group of 600 American oncologists - 56\% [25]. In Australia, more than $35 \%$ of gynecological oncologists demonstrated a high degree of emotional exhaustion. Close to $50 \%$ of them had considered a change of job in the previous 6 months [26]. In a group of nearly 400 hematological oncologists, a marked degree of emotional exhaustion and depersonalization was found in $32 \%$ of physicians [27].

\section{Discussion}

The above data confirm the universality of the prevalence of burnout syndrome among physicians of different specialties and from different countries. In the research cited above, the most frequently mentioned factor predisposing to burnout was work overload, mostly defined as work over $35 \mathrm{~h}$ a week $[12,19,20,28,29]$ and work during the weekend or at night $[12,19]$ with concomitant high expectations of ill people [22, 30, 31]. This work overload for a doctor means most frequently a necessity to establish more contacts with patients. Therefore, a basis of the burnout of physicians from different cultural circles, and multiple health service systems, is linked to their relationships with patients.

\section{Destructive games between patient and doctor}

It is easier to experience more strains in contact with demanding patients in conditions of longer work time, which in the above-quoted research and surveys was depicted as a factor predisposing to burnout $[12,19,20,28,29]$. What is more, the contact between a patient and a doctor is frequently not limited to the practical exchange of information between these two parties. Since, as always, contact involving a personal relationship may have for its participants different aims, and take the shape of destructive interpersonal games, it brings for a doctor a lot of strains, including emotional ones [32]. To depict examples of burden for physicians derived from such games we describe some of them, codified by authors of transactional analysis, beneath [32]. The crux of the games is depicted in Table I.

\section{Wooden leg}

We would consider it understandable for someone with a wooden leg to be less fit than a healthy man. Therefore, the crux of the game "wooden leg" is, by means of a given disability, justification for choices or behavior which in the average person may be considered unacceptable. Berne, in his book "Games People Play", described the example of 
Table I. Outline of the interpersonal games described in this work

\begin{tabular}{|ll|}
\hline Name of the game & Crux of the game \\
\hline Wooden leg & $\begin{array}{l}\text { Possessing a disability as a justification for choices or behavior which in the average } \\
\text { person may be considered unacceptable }\end{array}$ \\
\hline Why don't you... Yes, but & $\begin{array}{l}\text { The player reports a problem despite having been presented with solutions to it, to gain } \\
\text { confirmation that his/her issue is "insoluble" }\end{array}$ \\
\hline Now l've got you & $\begin{array}{l}\text { If one party of a usually not-clearly-defined contract even slightly exceeds its boundaries, } \\
\text { the other party, the player, thinks he/she is permitted to react in a forceful way, possibly } \\
\text { with full rage }\end{array}$ \\
\hline How do you get out of here? & $\begin{array}{l}\text { In case of failure of repeated mock efforts the player can avoid a possible } \\
\text { consequence of achieving success and feel "justified" in this situation }\end{array}$ \\
\hline Clinic & $\begin{array}{l}\text { Because both parties of a contract benefit from it they do not want to give it up, even } \\
\text { if there is really no need to continue it }\end{array}$ \\
\hline
\end{tabular}

a stammerer who had been searching only for the post of a salesman, even though he might have been able to take another job [32]. We may imagine that the inability to find a job as a salesman might have been used as an excuse to remain unemployed ("I cannot find a job as a salesman; therefore I am not capable of working at all").

In this game some dangers will arise both for the patient and for the doctor. If a doctor accepts the patient's game, he will wrongly assure him of his right to receive entitlements or privileges. Moreover, gaining benefits from this game will be the rationale behind remaining ill. However, if the doctor reveals his disapproval of the game, this may be treated as groundless rejection by the disabled man, all the more unjust because it has been made by a man called to provide him with help. In this situation a patient may lodge a complaint to the doctor's superiors, which for a doctor may result in various formal legal consequences.

Having an "ill man" in the family may constitute a benefit for his family members, who have an opportunity to justify their situation or activity (for example, "the relationships in our family would be quite different if we didn't have an impaired child"). After carrying out treatment, a marked improvement of such a patient's health may bring about a negative response from the patient's family towards a doctor.

\section{Why don't you... Yes, but}

This game is based on the fact that a man is still reporting a problem despite having been presented with solutions to it. It is compounded by a lack of help from his supporters, with a final lack of ideas on the doctor's part to reach a resolution. Initially, the "man with a problem" may gain a benefit in the shape of confirmation that his issue is "insoluble" ("I may be justified, because in this situation one can do nothing") or possessing a sense of his position having been defended ("I managed to win in spite of attempts to beat me"). In the doctor- patient relationship, this game may be revealed with the astonishing ineffectiveness of successive therapies regarding the patient's complaint (for example, one drug is considered to be ineffective, another is not tolerated, another is too expensive to buy, etc.) until the doctor's ideas for further treatment are exhausted. Over successive appointments, the patient may express his dissatisfaction with lack of effectiveness of the doctor's activities addressing his health problem.

\section{Now l've got you}

The basis for this game is a situation in which one party is obliged to perform a determined activity, while the second party performs another previously defined activity in exchange for something. If upon realizing such a contract exists one side even slightly exceeds the boundaries (especially those not clearly defined), the other side will react in a forceful way, able to vent all his rage.

In this game, the patient will go to the doctor expecting from him a cure. In turn, the doctor will expect from the patient reasonable cooperation in the conducted diagnostics and therapy. If the doctor is going to order successive accessory examinations or specialist advice due to an unclear clinical feature, the patient may respond in an aggressive manner, accusing him or the whole health service of incompetence (additionally he may lodge a complaint to all superiors of the doctor).

The benefit from this game for the player may constitute confirmation that other people are not fair to him, so in this way his hostile and untrusting approach to them is justifiable.

\section{How do you get out of here?}

This game may concern people under a treatment regimen, for example patients in hospital. The player - a patient - while staying in hospital, announces to those around him he wants to "get out of this nasty place as soon as possible" and he will do everything necessary to achieve this goal. During 
each and every ward round he raises the topic: "When at last are you going to discharge me?". But when the moment of discharge finally arrives, an "unexpected situation" arises, making leaving the hospital impossible, e.g. a sudden worsening of his health. In this way a man "desperate to get out" avoids returning to the outside world, at the same time having "a doctor's excuse" for it ("I tried so hard - this is why it is not my fault it failed").

\section{Clinic}

This game is based on a distinct mutual benefit within the framework of an informal contract, and the party who breaks the rules should be punished by the other side. An example of this game may be a situation where a patient is being treated in a renowned center, but despite protracted specialist treatment no cure has been provided. In this game, neither of the parties is really interested in the cure because, in the event of total health restoration, the patient would lose access to broad diagnostics and the constant care of top specialists, which means a sense of safety and his exceptionality. By the same token, the center would miss an established fee for his treatment, or an opportunity for further scientific analysis of this case. If a sudden and unexpected cure by a new doctor "unaware of the game" is found, the patient might bring a complaint against this doctor or the medical center (accusing the doctor of a hasty and careless attitude to the patient's complicated case, and in this way contesting obtained results of the treatment).

\section{Loss of personal resources as a result of contact with patients}

Excessively long working hours and patients' large demands are the most frequently mentioned factors predisposing to burnout given in research $[12,19,20,22,28-31]$. These make doctors devote an ever greater amount of personal resources to patients. According to Hobfoll [33] personal resources comprise possessed skills and abilities, socioprofessional status, energy resources (like money or time) and material objects. The essence of one's satisfaction is conservation of resources. Loss of some resources or lack of their expected increase may constitute a stressful situation [33]. To recompense for a loss of some resources an individual may use other acquired resources. In the abovementioned situation, a doctor invests his own resources in professional work at the cost of different possibilities, for example time devoted to the family. But when this investment does not give the expected results, or leads to further diminishing of resources (as in the case of consecutive strains due to the above-mentioned games), not being replaced with a satisfactory increase in other resources, stress, disorganization of functioning, and a sense of lack of effectiveness are going to occur. And this constitutes grounds for burnout syndrome.

\section{Sense of lack of competence at work (I can't get no satisfaction)}

According to Cherniss, the lack of possibility of professional satisfaction, the sense of lack of competence at work, is of key importance for the occurrence of burnout syndrome. Cherniss distinguishes 4 types of attitude to professional work, and 2 of them predispose to burnout syndrome [34]. The first type is a social activist, who does more for his clients than is required. The second one is an artisan, who still aspires to improvement of his professional competence. Both types of people, under conditions of recurrent strain between the committed investment of their own resources and the excessive demands issued at work, undergo emotional exhaustion. They first experience the feeling that they are not gaining professional competence. That is, they sense the lack of confirmation of how effective they are at work. It resembles the sense of low professional accomplishment previously described by Maslach [4]. So in the doctor-patient relationship, the basis for a doctor to regard his competence as low will be the repeated demands and complaints of "difficult patients", despite his very real and strong concern for their problems.

Cherniss presents two other types of people with a different attitude to work, who do not sense so strongly the association between a clients' concerns and their competence [34]. They are the careerist, for whom their job is only a source of material benefits and professional prestige, and the self-investor, who finds life satisfaction mainly outside his work.

\section{Burnout as a loss of the sense of existence}

An element of disappointment coming from contact with a recipient of help was already considered important for the pathogenesis of burnout by Freudenberger [1]. According to Pines, it contributes to the loss of the significance of work and even the meaning of life, perceived predominantly through the prism of work by someone involved in his profession [35].

A firm feeling of the meaning of life is the most important power motivating man, according to Frankl [36]. It gives direction to our actions, makes them coherent, and our personal value system is in direct correlation with it. Furthermore, the loss of the meaning of life clinically manifests itself as apathy (existential emptiness) or existential neurosis.

Therefore, experiencing a lack of fulfillment at work, especially due to difficult contact with patients, is of great significance for doctors today. It 
may become for them a cause of the loss of the meaning of life [37].

\section{Conclusions}

The amazing universality of burnout syndrome among doctors working in different countries and under diverse conditions suggests that the essential reason for burnout is grounded in the common aspect of their daily work: their relationship with patients. Excessive psycho-emotional exploitation resulting from contact with patients is not only detrimental to the health of doctors committed to providing a professional service, but it additionally affects the quality of medical services provided, thereby negatively influencing patients' health, as well. Therefore, to ensure that the good of the patient remains the focus of the health service providing the care, the needs and wellbeing of the doctor should also be taken care of.

\section{References}

1. Freudenberger HJ. Staff burn-out. J Soc Issues 1974; 30: 159-65.

2. Sęk H. Wypalenie zawodowe. Przyczyny i zapobieganie [Polish]. $3^{\text {rd }}$ ed. Warszawa, PWN; 2006.

3. Borritz M, Rugulies R, Christensen KB, Villadsen E, Kristensen TS. Burnout as a predictor of self-reported sickness absence among human service workers: prospective findings from three year follow up of the PUMA study. Occup Environ Med 2006; 63: 98-106.

4. Maslach C. Job burnout: new directions in research and intervention. Curr Dir Psychol Sci 2003; 12: 189-92.

5. Maslach C. Understanding burnout: definitional issues in analyzing a complex phenomenon. In: Paine WS (ed.) Job stress and burnout. Beverly Hills, CA: Sage; 1982; 29-40.

6. Perlman B, Hartman EA. Burnout: summary and future research. Hum Relat 1982; 35: 283-305.

7. Pines A, Aronson E. Career burnout: causes and cures. Free Press, New York 1988.

8. Sharma A, Sharp DM, Walker LG, Monson JR. Stress and burnout in colorectal and vascular surgical consultants working in the UK National Health Service. Psychooncology 2008; 17: 570-6.

9. Sadat-Ali M, Al-Habdan IM, Al-Dakheel DA, Shriyan D. Are orthopedic surgeons prone to burnout? Saudi Med J 2005; 26: 1180-2.

10. Frade Mera MJ, Vinagre Gaspar R, Zaragoza García I, et al. Burnout syndrome in different intensive care units. Enferm Intensiva 2009; 20: 131-40.

11. Morais A, Maia P, Azevedo A, Amaral C, Tavares J. Stress and burnout among Portuguese anaesthesiologists. Eur J Anaesthesiol 2006; 23: 433-9.

12. Kinzl JF, Traweger C, Biebl W, Lederer W. Burnout and stress disorders in intensive care doctors [German]. Dtsch Med Wochenschr 2006; 131: 2461-4.

13. Lee FJ, Stewart M, Brown JB. Stress, burnout, and strategies for reducing them: what's the situation among Canadian family physicians? Can Fam Physician 2008; 54: 234-5.

14. Esteva M, Larraz C, Jiménez F. Mental health in family doctors: effects of satisfaction and stress at work. Rev Clin Esp 2006; 206: 77-83.
15. Adám S, Torzsa P, Gyorffy Z, Vörös K, Kalabay L. Frequent high-level burnout among general practitioners and residents. Orv Hetil 2009; 150: 317-23.

16. Goehring C, Bouvier Gallacchi M, Künzi B, Bovier P. Psychosocial and professional characteristics of burnout in Swiss primary care practitioners: a cross-sectional survey. Swiss Med Wkly 2005; 135: 101-8.

17. Arigoni F, Bovier PA, Mermillod B, Waltz P, Sappino AP. Prevalence of burnout among Swiss cancer clinicians, paediatricians and general practitioners: who are most at risk? Support Care Cancer 2009; 17: 75-81.

18. Soler JK, Yaman H, Esteva, et al. Burnout in European family doctors: the EGPRN study. Fam Pract 2008; 25: 245-65.

19. Johns MM 3rd, Ossoff RH. Burnout in academic chairs of otolaryngology: head and neck surgery. Laryngoscope 2005; 115: 2056-61.

20. Cruz OA, Pole CJ, Thomas SM. Burnout in chairs of academic departments of ophthalmology. Ophthalmology 2007; 114: 2350-5.

21. Kumar S, Fischer J, Robinson E, Hatcher S, Bhagat RN. Burnout and job satisfaction in New Zealand psychiatrists: a national study. Int J Soc Psychiatry 2007; 53: 306-16.

22. Bressi C, Porcellana M, Gambini O, et al. Burnout among psychiatrists in Milan: a multicenter survey. Psychiatr Serv 2009; 60: 985-8.

23. Czekajska-Chehab E, Okła W, Drop A, Skrzypek M. The professional burnout syndrome in radiologists. Ann Univ Mariae Curie Sklodowska Med 2003; 58: 254-60.

24. Glasberg J, Horiuti L, Novais MA, et al. Prevalence of the burnout syndrome among Brazylian medical oncologists. Rev Assoc Med Bras 2007; 53: 85-9.

25. Whippen DA, Canellos GP. Burnout syndrome in the practice of oncology: results of a random survey of 1,000 oncologists. J Clin Oncol 1991; 9: 1916-20.

26. Stafford L, Judd F. Mental health and occupational wellbeing of Australian gynaecologic oncologists. Gynecol Oncol 2010; 116: 526-32.

27. Bressi C, Manenti S, Porcellana M, et al. Haematooncology and burnout: an Italian survey. Br J Cancer 2008; 98: 1046-52.

28. Al-Dubai SA, Rampal KG. Prevalence and associated factors of burnout among doctors in Yemen. J Occup Health 2010; 52: 58-65.

29. Leiter MP, Frank E, Matheson TJ. Demands, values, and burnout: relevance for physicians. Can Fam Physician 2009; 55: 1224-5.

30. Gtebocka A, Lisowska E. Professional burnout and stress among Polish physicians explained by the Hobfoll resources theory. J Physiol Pharmacol 2007; 58 (Suppl. 5): 243-52.

31. Lim RC, Pinto C. Work stress, satisfaction and burnout in New Zealand radiologists: comparison of public hospital and private practice in New Zealand. J Med Imaging Radiat Oncol 2009; 53: 194-9.

32. Berne E. Games people play: the basic handbook of transactional analysis. 7th ed. Ballantine Books, New York 1996.

33. Hobfoll SE. Conservation of resources: a new attempt at conceptualizing stress. Am Psychol 1989; 44: 513-24.

34. Cherniss C. Staff burnout - job stress in the human services. Sage Publications, Beverly Hills 1980.

35. Pines A, Aronson E. Career burnout: causes and cures. Free Press, New York 1988.

36. Frankl VE. Man's search for meaning. Beacon Press, Boston 1959.

37. Sablik Z, Samborska-Sablik A. Can religious and philosophical values counteract burnout syndrome? In: Janowski K, Steuden S, editors. Biopsychological aspects of health and disease. CPPP Scientific Press, Lublin 2009; 158-68. 